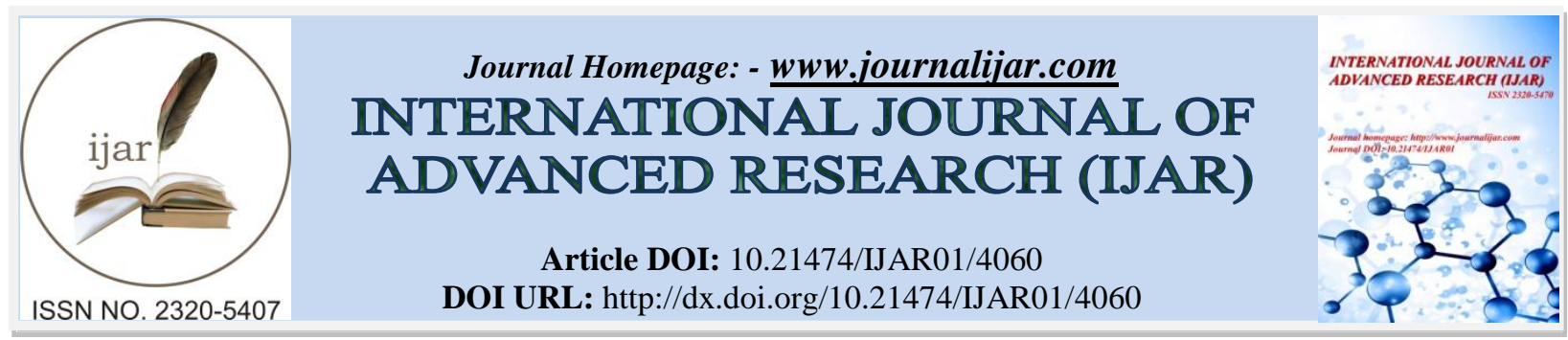

RESEARCH ARTICLE

\title{
SILENT PULMONARY EMBOLISM: INCIDENCE AND RISK FACTORS IN INDIAN PATIENTS WITH LOWER LIMB DVT
}

\author{
Dr.Shanmugavelayutham.C, Dr. Elancheralathan.K, Dr.Thulasikumar.G, Dr.Deepan kumar.B and \\ Dr.Lakshmidharan.M. \\ Department of Vascular Surgery, Stanley Medical College, Chennai.
}

\section{Manuscript Info}

Manuscript History

Received: 26 February 2017

Final Accepted: 28 March 2017

Published: April 2017

Key words:-

Silent Pulmonary Embolism, Deep

Venous Thrombosis

\begin{abstract}
Objective: The aim of our study is to evaluate the incidence of silent pulmonary embolism in Indian patients with lower limb deep venous thrombosis.

Materials and Methods: 44 patients with acute lower limb proximal DVT were prospectively studied with respect to various clinical factors. All patients had no respiratory symptoms and were submitted to CT pulmonary angiography for active investigation of Pulmonary Embolism.

Results: 33 out of 44 patients were found to have silent PE (75\%). Higher incidence of silent PE found in older age, male sex, right side involvement and unprovoked DVT. Of these risk factors, Unprovoked DVT had statistically significant higher incidence for Silent PE than patients with provoked DVT $83.38 \%$ vs. 50\% (P-0.0451).

Conclusion: Above data (75\%) clearly shows that silent PE is very frequent in Indian patients with deep venous thrombosis. Unprovoked DVT was single most significant risk factor associated with silent PE. This very high incidence supports the need for screening and high levels of suspicion regarding this complication especially in those with proximal unprovoked DVT.
\end{abstract}

Copy Right, IJAR, 2017,. All rights reserved.

\section{Introduction:-}

Pulmonary embolism (PE) with its associated mortality is the most devastating complication of Deep Venous Thrombosis (DVT). ${ }^{9,10}$ There are various studies which show that Silent Pulmonary Embolism (SPE) is associated with increased conversion to symptomatic Pulmonary Embolism and with increased fatality. ${ }^{8,9}$ Western literatures shows incidence of Silent PE from 50\% to $80 \%{ }^{1,2,8,9}$ The aim of our study is to evaluate the incidence of silent pulmonary embolism in Indian patients with lower limb deep venous thrombosis and analyzes the potential risk factors in patients with silent PE.

\section{Methodology:}

This is prospective observational study done in Stanley medical college in patients reporting to vascular surgery department with acute lower limb DVT from Jan 2015- Dec 2016. Totally 44 patients with acute lower limb DVT were studied with respect to various clinical factors. Only those with Proximal DVT were included in the study (involvement of deep venous thrombosis from popliteal vein and above). ${ }^{5,6}$ All these patients had no symptoms (dyspnea, cough, pleuritic pain, haemoptysis, syncope) or signs (tachycardia, tachypnoea, hypotension, fall in 
oxygen saturation) suggestive of PE. ${ }^{2,3,4}$ These patients were submitted to CT pulmonary angiography for active detection of Pulmonary Embolism. All these patients were subjected to routine blood investigations, chest $\mathrm{x}$-ray, ECG, echocardiogram, Ultra sonogram of Abdomen and Pelvis with appropriate hypercoagulable work up.

\section{Results and Discussion:-}

Incidence:-

Out of 44 patients with acute lower limb proximal DVT, 33 were found to have silent pulmonary embolism with incidence of $75 \%$. Data clearly indicate that Silent PE is very frequent in these groups of Indian patients with lower limb DVT.

Age:

Table 1:- Age Group Invoiving Silent Pulonary Embolism.

\begin{tabular}{|c|c|c|c|c|}
\hline S.NO. & \multirow{2}{*}{ AGE GROUP } & \multicolumn{2}{|c|}{ SILENT PULONARY EMBOLISM } & \multirow{2}{*}{ INCIDENCE } \\
\cline { 3 - 5 } & & POSITIVE & NEGATIVE & \\
\hline 1 & $\leq 30$ YEARS & 11 & 2 & $81.81 \%$ \\
\hline 2 & $31-40$ YEARS & 11 & 3 & $72.72 \%$ \\
\hline 3 & $41-50$ YEARS & 5 & 5 & $60.51 \%$ \\
\hline 4 & $51-60$ YEARS & 2 & 1 & $100 \%$ \\
\hline 5 & $>60$ YEARS & 4 & 0 & \\
\hline
\end{tabular}

All Patients (four) in age group of > 60years were found to be silent PE positive with incidence $100 \%$. Youngest patient in this study was 15 years girl with thrombosis upto infrarenal inferior vena cava and oldest was 82 years female with left lower limb iliofemoral DVT.

Table 2:- Characteristics Features Of Silent Pe Patients

\begin{tabular}{|l|l|l|l|}
\hline S.NO. & FEATURES & NUMBER ( N-33) & PERCENTAGE \\
\hline 1. & MEAN AGE (15 - 82 YEARS) & 39.69 YEARS & - \\
\hline \multirow{3}{*}{2.} & $\begin{array}{l}\text { GENDER: } \\
\text { A) MALE }\end{array}$ & 22 & $66.67 \%$ \\
\cline { 2 - 4 } & B) FEMALE & 11 & $33.33 \%$ \\
\hline \multirow{5}{*}{3.} & $\begin{array}{l}\text { EXTENT OF DVT : } \\
\text { A) ILIOFEMORAL DVT }\end{array}$ & 21 & $63.63 \%$ \\
\cline { 2 - 4 } & B) FEMOROPOPLITEAL & 10 & $30.3 \%$ \\
\cline { 2 - 4 } & C) INFERIOR VENA CAVA & 2 & $6.06 \%$ \\
\hline \multirow{5}{*}{4} & LIMB INVOLVED: & 12 & $36.36 \%$ \\
\cline { 2 - 4 } & A) RIGHT SIDE & 18 & $54.54 \%$ \\
\cline { 2 - 4 } & B) LEFT SIDE & 3 & $9.09 \%$ \\
\hline \multirow{2}{*}{5} & UNOTH SIDES & 27 & $18.81 \%$ \\
\cline { 2 - 4 } & PROVOKOKED DVT & 6 & \\
\hline
\end{tabular}

\section{Gender:-}

Male patients were majority in our study (22/33) constituting $66.67 \%$. Male patients had higher incidence of Silent PE than female patients $78.57 \%$ vs. $68.75 \%$.

\section{Limb Involved:-}

Overall prevalence of DVT is more on the left side constituting $55.56 \%$ of the cases. But incidence of Silent PE was found to be more on right side compared to left side (80\% vs. $72 \%)$. In this study, 4 had bilateral DVT with incidence of $75 \%$ (3 out of 4 ).

\section{Extent Of DVT:-}

All the patients included in our study were proximal DVT patients. Of these, that involving iliofemoral segment had higher incidence of Silent PE than those involving femoropopliteal segment (84\% vs. $62.5 \%$ ). Out of three patients with inferior vena cava involvement, two were positive for silent PE (66.67\%). 
Provoked / Unprovoked Dvt:-

Table 3:- Provoked / Unprovoked Dvt In Silent Pe.

\begin{tabular}{|l|l|l|l|l|}
\hline \multirow{2}{*}{ S.NO. } & & \multicolumn{2}{|l|}{ SILENT PULMONARY EMBOLISM } & \multirow{2}{*}{ INCIDENCE } \\
\cline { 3 - 4 } & & POSITIVE & NEGATIVE & \\
\hline 1 & UNPROVOKED DVT & 27 & 5 & $83.38 \%$ \\
\hline 2 & PROVOKED DVT & 6 & 6 & $50 \%$ \\
\hline \multicolumn{2}{|l|}{ P -0.0451 (STATISTICALLY SIGNIFICANT) } & & \\
\hline
\end{tabular}

Unprovoked DVT patients were the majority in this study (81.81\%) and also they had significant higher incidence of Silent PE than patients with provoked DVT ( $83.38 \%$ vs. $50 \%)$.

\section{Ct Pulmonary Angiography:-}

Majority of patients had involvement of segmental pulmonary arteries constituting $84.8 \%$. Also four patients in our study had involvement of one main pulmonary artery constituting $12 \%$ of patients but had no symptoms or signs.

Figure 1:- CT Pulmonary angiogram: Site marked with circle indicate the occluded segment of pulmonary artery: A) Main Pulmonary B) Lobar C) Segmental Artery.
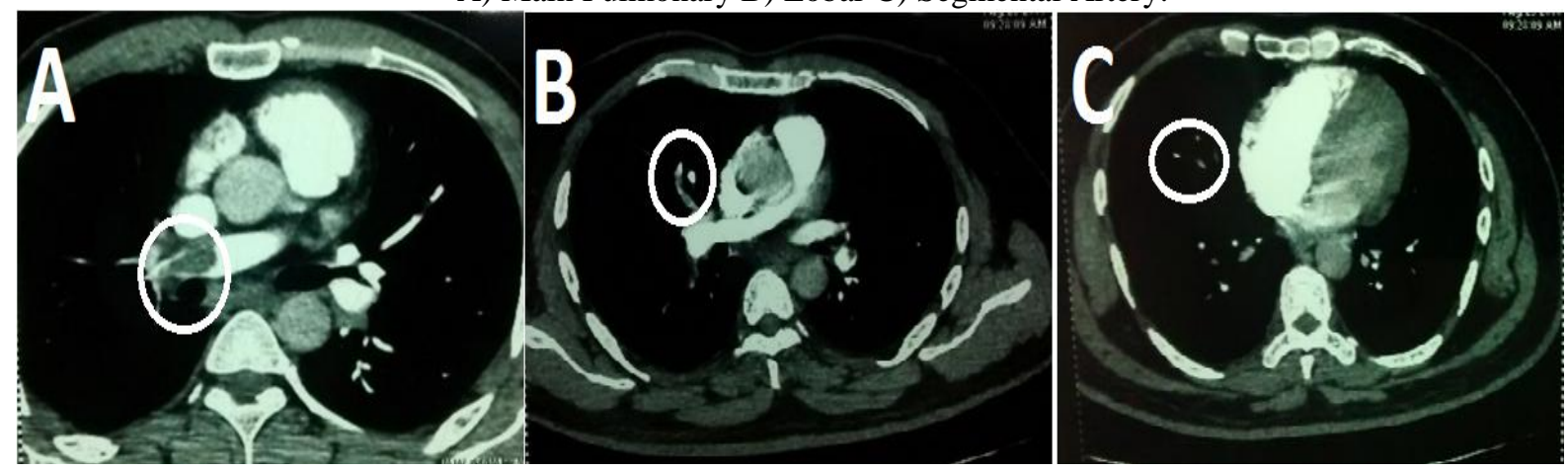

Those factors like blood investigations, X-ray, ECG and Echocardiography were not contributory for detecting Silent PE.

Table 4:- Incidence Of Silent Pe - Comparison

\begin{tabular}{|c|c|c|c|}
\hline S.NO & AUTHOR / YEAR & NUMBER & INCIDENCE \\
\hline 1 & ${\text { KRUTMAN } 2013^{8}}^{8}$ & $38 / 52$ & $72 \%$ \\
\hline 2 & ${\text { FUSTER } 2014^{3}}^{3}$ & $68 / 103$ & $66 \%$ \\
\hline 3 & ${\text { JIMÉNEZ } 2006^{6}}^{6}$ & $28 / 91$ & $31 \%$ \\
\hline
\end{tabular}

Incidence of Silent PE in Krutman et $\mathrm{al}^{8}$, Fuster et $\mathrm{al}^{3}$ and Jiménez et $\mathrm{al}^{6}$ studies were $72 \%, 66 \%$ and $31 \%$ respectively. Incidence in this present study was $75 \%$. This clearly shows there is a high incidence of PE in Indian subset of population.

\section{Conclusion:-}

Above data (75\%) clearly shows that silent PE is very frequent in Indian patients with deep venous thrombosis, with Proximal, Unprovoked DVT as significant risk factors. This very high incidence supports the need for screening and high levels of suspicion regarding this complication especially in those with proximal unprovoked DVT.

\section{References:-}

1. Anja boc et al., Unprovoked proximal venous thrombosis is associated with an increased risk of asymptomatic pulmonary embolism, Thrombosis Research 133 (2014) 1011-1015

2. Fenghe Li et al., Risk factors associated with the occurrence of silent pulmonary embolism in patients with deep venous thrombosis of the lower limb, Phlebology 2014, Vol. 29(7) 442-446

3. Fuster et al., Should we look for silent pulmonary embolism in patients with deep venous thrombosis? BMC Cardiovasc Disord. 2014 Dec 8;14:178

4. Haimovici's Vascular Surgery, 6edition 
5. Hallet's Comprehensive.Vascular.and.Endovascular.Surgery, 2nd edition.

6. Jiménez D, Díaz G, Marín E, et al. The risk of recurrent venous thromboembolism in patients with unprovoked symptomatic deep vein thrombosis and asymptomatic pulmonary embolism. Thromb Haemost. 2006;95:562566

7. Kakkar et al., Pulmonary Embolism in Medical Patients: An Autopsy-Based Study, Clinical and Applied Thrombosis/ Hemostasis, Volume 14 Number 2, April 2008 159-167

8. Krutman et al, Risk of asymptomatic pulmonary embolism in patients with deep venous thrombosis, J Vasc Surg Venous Lymphat Disord. 2013 Oct;1(4):370-5.

9. Parakh et al., Pulmonary Embolism: A Frequent Occurrence in Indian Patients with Symptomatic Lower Limb Venous Thrombosis, Asian J Surg 2006;29(2):86-91

10. Rutherford's vascular surgery, volume- $1,8^{\text {th }}$ edition.

11. Stein at al., Silent Pulmonary Embolism in Patients with Deep Venous Thrombosis: A Systematic Review, The American Journal of Medicine (2010) 123, 426-431

12. Tzoran et al., Silent pulmonary embolism in patients with proximal deep vein thrombosis in the lower limbs, Journal of Thrombosis and Haemostasis, 10: 564-571

13. Wesley S.Moore's Vascular and Endovascular surgery, $8^{\text {th }}$ edition 